\title{
A Laboratory-based Approach to Biological Control of Snails
}

\author{
Fred A Lewis ${ }^{+}$, Matty Knight, Charles S Richards
}

\author{
Biomedical Research Institute, 12111 Parklawn Drive, Rockville, MD 20852, USA
}

\begin{abstract}
Development of Schistosoma mansoni in the intermediate host Biomphalaria glabrata is influenced by a number of parasite and snail genes. Understanding the genetics involved in this complex host/ parasite relationship may lead to an often discussed approach of introducing resistant B. glabrata into the field as a means of biological control for the parasite. For the snail, juvenile susceptibility to the parasite is controlled by at least four genes, whereas one gene seems to be responsible for adult nonsusceptibility. Obtaining DNA from F2 progeny snails from crosses between parasite-resistant andsusceptible snails, we have searched for molecular markers that show linkage to either the resistant or susceptible phenotype. Both restriction fragment length polymorphism (RFLP) and random amplified polymorphic DNA (RAPD) approaches have been used. To date, using a variety of snail and heterologous species probes, no RFLP marker has been found that segregates with either the resistant or susceptible phenotype in F2 progeny snails. More promising results however have been found with the RAPD approach, where a $1.3 \mathrm{~kb}$ marker appears in nearly all resistant progeny, and a $1.1 \mathrm{~kb}$ marker appears in all susceptible progeny.
\end{abstract}

Key words: snails - genetic susceptibility - biological control - schistosomiasis - Biomphalaria glabrata Schistosoma mansoni - resistance - susceptibility

Infection of the planorbid snail Biomphalaria glabrata by the helminth parasite Schistosoma mansoni depends on genes from both snail and parasite (Richards \& Shade 1987). A number of laboratory-derived stocks of B. glabrata have been used to sort out this complex genetic relationship. The use of snails possessing different susceptibility phenotypes, and progeny from their crosses, might enable investigators to determine molecular factors important in these phenotypes. To develop the snail populations for study, use of pigmentation markers has been essential for verifying that progeny snails in question result from cross-, and not by self-, fertilization (Richards et al. 1992). This report describes attempts to determine molecular markers that segregate with either susceptibility or resistance to the parasite in F2 progeny from crosses between $B$. glabrata snails which are either susceptible or resistant to S. mansoni. The techniques used for this study encompassed both restriction fragment length polymorphism (RFLP) and random amplified polymorphic DNA (RAPD) approaches.

\section{MATERIALS AND METHODS}

Snails - Crosses were made from M-line susceptible (Newton 1953) and BS-90 resistant $B$. glabrata snails (Paraense \& Correa 1963). Infection phenotypes of progeny F2 snail cohorts was assessed by exposing 5-8 $\mathrm{mm}$ dia. snails to $S$.

\footnotetext{
${ }^{+}$Corresponding author. Fax: 301-770-4756

Received 16 April 1997

Accepted 30 June 1997
}

mansoni miracidia. Snails were examined weekly and scored as positive either by establishment of primary or secondary sporocysts, or by shedding of cercariae 4-5 weeks after exposure.

Molecular analysis - DNA was isolated from the snails by standard procedures (Knight et al. 1991). The quality of DNA was determined by horizontal flat-bed gel electrophoresis on $0.6 \%$ agarose gels.

For RFLP analysis, genomic DNA was digested with a number of restriction enzymes, and the fragments separated by flat-bed electrophoresis through a $0.6 \%$ agarose gel, then transferred to either a nylon or nitrocellulose membrane according to the technique of Southern (Southern 1975). Hybridization with radioisotopically-labelled probe pSM389 (McCutchan et al. 1984), or several homologous probes (unpublished) was followed by washing, then autoradiography on Kodak X-Omat film with intensifying screens at $-70^{\circ} \mathrm{C}$.

For the RAPD-polymerase chain reaction, conditions used were those described by Williams et al. (1990). A series of 20 arbitrary oligonucleotide primers were used (Operon Technologies, Inc, Alameda, CA, USA), and amplifications carried out with Taq DNA polymerase. Amplified products were initially screened by ethidium bromide staining of gels, and more sensitive resolution of fragments by silver staining of $4 \%$ polyacrylamide gels.

The genetic heritability of genotypically stable markers, as employed with both molecular analyses, was determined with DNA from F2 progeny snails resulting from crosses between resistant and susceptible parents. 


\section{RESULTS}

Cohort snails from the adult population of F2 progeny snails, derived from crosses between susceptible and resistant parents, developed a resistant:susceptible phenotypic ratio of approximately $3: 1$. This ratio would be expected if there were one gene involved in resistance to this parasite strain and inherited in a Mendelian fashion.

When DNA from F2 progeny snails were subjected to RFLP analysis, most alleles present were inherited in a co-dominant fashion. However, to date no association with either resistance or susceptibility was noticed with any of the markers used. This was the case regardless if either homologous or heterologous probes were tested.

Experiments using the RAPD approach indicated that the majority of primers tested showed no polymorphisms between the various snail lines tested, or they were not reproducible among individual isolates from the same line. Only two primers were initially useful for distinguishing snail lines. Amplification with primer OPA-01 produced a major $180 \mathrm{bp}$ marker in resistant snails, and a $400 \mathrm{bp}$ fragment in susceptible snails. With primer OPA-06, a $600 \mathrm{bp}$ marker was found only in resistant snails. A major specific marker (1100 bp) in susceptible snails was amplified with OPA-06. Further studies in the reproducibility of these major markers showed that these may represent invariant structural genotypic differences between snails of the two separate phenotypes (Larson et al. 1996).

Strain specific markers were inherited in a codominant fashion in the majority of $\mathrm{F} 2$ progeny from crosses between susceptible and resistant snails. From infectivity studies however there was no apparent linkage in the inheritance of these markers to the parasite susceptibility phenotypes of the progeny snails.

\section{DISCUSSION}

These studies summarize attempts to determine markers that segregate according to susceptibility phenotypes among progeny snails derived from crosses between resistant and susceptible parents. Although snail strain differentiation can be accomplished by such techniques as RFLP and RAPD analysis, to date we have not been able to show linkage of susceptibility phenotypes with the RFLP approach, although some promising results have been obtained with the RAPD method with several of the markers used.

Such approaches have considerable promise, not only in this type of study, but in studies of genetic diversity of populations in the field. For instance Langand et al. (1993) showed the usefulness of the RAPD approach for evaluating genetic diversity within the genus Bulinus. A recent report by Vidigal et al. (1994) showed similar ge- netic diversity, using a comparable approach, among field isolates of B. glabrata in Brazil.

The ability to determine resistance or susceptibility markers in field populations would be an important component of studies to potential biological control measures employing the use of refractory snails. The genetic flow of markers within a population would have to be known before the feasibility of this technique can be realized. Since many complex issues determine susceptibility and transmission potential in any population of snails, we are hopeful that approaches such as ours described here can be useful for developing additional control measures for schistosomiasis in the near future.

\section{REFERENCES}

Knight M, Brindley PJ, Richards CS, Lewis FA 1991. Schistosoma mansoni: Use of a cloned ribosomal RNA gene probe to detect restriction fragment length polymorphisms in the intermediate host Biomphalaria glabrata. Exp Parasitol 73: 285-294.

Langand J, Barral V, Delay B, Jourdane J 1993. Detection of genetic diversity within snail intermediate hosts of the genus Bulinus by using random amplified polymorphic DNA markers (RAPDs). Acta Tropica 55: 205-215.

Larson SE, Andersen PL, Miller AN, Cousin CE, Richards CS, Lewis FA, Knight M 1996. Use of RAPD-PCR to differentiate genetically defined lines of the intermediate host of Schistosoma mansoni, Biomphalaria glabrata. J Parasitol 82: 237-244.

McCutchan TF, Simpson AJG, Mullins JA, Sher A, Nash TE, Lewis F, Richards C 1984. Differentiation of schistosomes by species, strain, and sex by using cloned DNA markers. Proc Nat Acad Sci USA 81: 889-893.

Newton WL 1953. The inheritance of susceptibility to infection with Schistosoma mansoni in Australorbis glabratus. Exp Parasitol 2: 242-257.

Paraense WL,Correa L 1963. Variation in susceptibility of populations of Australorbis glabratus to a strain of Schistosoma mansoni. Rev Inst Med Trop S Paulo 5: $15-22$

Richards CS, Knight M, Lewis FA 1992. Genetics of Biomphalaria glabrata and its effect on the outcome of Schistosoma mansoni infection. Parasitol Today 8: 171-174.

Richards CS, Shade PC 1987. The genetic variation of compatibility in Biomphalaria glabrata and Schistosoma mansoni. J Parasitol 73: 1146-1151.

Southern EM 1975. Detection of specific sequences among DNA fragments separated by gel electrophoresis. J Mol Biol 58: 503-517.

Vidigal EM, Neto ED, Carvalho OS, Simpson AJG 1994. Biomphalaria glabrata: extensive genetic variation in Brazilian isolates revealed by random amplified polymorphic DNA analysis. Exp Parasitol 79: $187-$ 194.

Williams JGK, Hanafey MK, Rafalski JA, Tingey SV 1990. DNA polymorphisms amplified by arbitrary primers are useful as genetic markers. Meth Enzymol 218: 704-740. 